Acta Biologica Plantarum Agriensis 5(1): 33 (2017) ISSN 2061-6716 (Print), 2063-6725 (Online)

http://abpa.ektf.hu/
DOI:10.21406/abpa.2017.5.1.33

$4^{\text {th }}$ CC 2017 Abstract

Lecture

\title{
REMARKABLE FINDS OF BRYOPHYTES IN HUNGARY DURING THE LAST TWO YEARS (2015-2017)
}

Az elmúlt két év (2015-2017) magyarországi mohaflorisztikai kutatásainak jelentősebb eredményei

\author{
Peter ErzBerger ${ }^{1}$, Csaba NÉmeth ${ }^{2}$, József NAGY33, Kornél BarÁth ${ }^{4}$, János CsiKY5,
} Jan Eckstein ${ }^{6}$, Attila MesterháZY7 ${ }^{7}$, Andor Kovács ${ }^{3}$ \& Beáta PAPP8

\footnotetext{
${ }^{1}$ Independent researcher, Berlin, Germany; ${ }^{2}$ MTA Centre for Ecological Research, GINOP Sustainable Ecosystems Group, Tihany, Klebersberg Kuno út 3, Hungary; ${ }^{3}$ Szent István University, Faculty of Horticultural Science, Department of Botany and Soroksár Botanical Garden, Budapest, Villányi út 29-43., Hungary; ${ }^{4}$ Institute of Biology, Savaria Campus, Eötvös Loránd University, Szombathely, Károlyi Gáspár tér 4., Hungary; ${ }^{5}$ University of Pécs, Faculty of Sciences, Institute of Biology, Department of Ecology, Pécs, Ifjúság u. 6., Hungary; ${ }^{6}$ Independent researcher, Göttingen, Germany; ${ }^{7}$ Directorate of Hortobágy National Park, Debrecen, Sumen u.2, Hungary; ${ }^{8}$ Hungarian Natural History Museum, Budapest, Hungary, Budapest, Pf. 137; e-mail: erzberger.peter@gmail.com
}

Extant occurrences of 9 species without recent data (DD, DD-va in the Hungarian bryophyte redlist of 2010) were discovered in the period 2015-2017: Brachythecium campestre (Börzsöny: 8180.1, Mecsek: 9875.2, Vendvidék: 9163.2, Tiszántúl: 8496.2), B. plumosum (Zempléni-hg.: 7594.1, Mátra: 8186.1, Vértes: 8476.3), Bryum archangelicum (Börzsöny: 8179.1), Ephemerum serratum (=E. stoloniferum (Hedw.) L.T. Ellis \& M.J. Price) (Börzsöny: 8080.3, Őrség: 9164.3), Jungermannia subulata (Mecsek: 9776.4), Marsupella emarginata (Börzsöny: 8079.2), Orthotrichum rogeri (Zemplénihg.: 7894.3), Pseudoleskea saviana (Mátra: 8186.1, Börzsöny: 8079.2, 8079.4), Schistidium confertum (Börzsöny: 8079.2, Mátra: 8186.1).

22 taxa were first recorded in Hungary since november 2015: Barbilophozia hatcheri (Budai-hg.: 8579.2), Brachythecium curtum (Zempléni-hg.: 7594.1, Börzsöny: 8079.4), Bryum tenuisetum (Csepel-sziget: 8679.2, Belső Somogy: 9971.1, Kemeneshát: 8768.1, Kőszegi-hg.: 8665.2), Campylopus subulatus (Kemeneshát: 8967.1), Crossidium squamiferum (Börzsöny: 8279.2), Didymodon tophaceus subsp. erosus (Duna-Tiszaköze: 9786.1), D. tophaceus subsp. sicculus (Duna-Tisza-közé: 9786.1, 9280.4, 8781.1), Ditrichum lineare (Zempléni-hg.: 7494.4), Fissidens bambergeri (Zempléni-hg.: 7494.2, Bükk: 8088.1, Börzsöny: 7979.4, 8179.1, 8180.1, Visegrádi-hg.: 8279.2, 8280.3, Budaihg.: 8479.1, 8479.4, Gerecse: 8377.1, Vértes: 8675.2, Kőszegi-hg.: 8664.4, 8665.1, Vendvidék: 9162.2, Zala: 9166.4), F. crispus (Börzsöny: 8079.2), Fossombronia incurva (Visegrádi-hg.: 8279.3, Őrség: 9164.3, Geresdi-dombság: 9777.3), Heterocladium heteropterum (Kőszegi-hg.: 8664.2), Pellia neesiana (Vendvidék: 9062.4, 9162.2), Plagiothecium latebricola (Kőszegi-hg.: 8664.2), Rhabdoweisia crispata (Kőszegi-hg.: 8664.2), Riccia beyrichiana (Visegrádi-hg.: 8279.2), Seligeria acutifolia (Pilis: 8279.4), Sematophyllum adnatum (Kemeneshát: 8967.1), Syntrichia ruralis var. epilosa (Keszthelyi-hg.: 9270.1, Kőszegi-hg.: 8665.1), Ulota crispula (Zempléni-hg.: 7594.1, Mátra: 8085.3, Börzsöny: 8080.1, Balatonfelvidék: 9171.1, Kőszegi-hg.: 8664.2, 8664.4, 8665.1, 8565.3, Vendvidék: 9062.4, 9163.1, Őrség: 9263.2, Kemeneshát: 8967.1, Zselic: 9873.2), U. intermedia (Zempléni-hg.: 7594.3, Börzsöny: 8079.2, Kőszegi-hg.: 8664.2, Vas-hegycsoport: 8764.4, Vendvidék: 9062.4, Őrség: 9164.3, 9264.1, Zselic: 9873.2), and Zygodon forsteri (Balatonfelvidék: 9071.3, 9171.1). 